\title{
Bezafibrate as differentiating factor of human myeloid leukemia cells
}

\author{
R. Scatena ${ }^{\star, 1}$, G. Nocca ${ }^{1}$, P. De Sole ${ }^{1}$, C. Rumi ${ }^{2}$, P. Puggioni ${ }^{2}$, \\ F. Remiddi ${ }^{3}$, P. Bottoni ${ }^{1}$, S. Ficarra ${ }^{4}$ and B. Giardina ${ }^{1}$ \\ 1 Institute of Chemistry and Clinical Chemistry, Catholic University, Rome, Italy \\ 2 Institute of Hematology, Catholic University, Rome, Italy \\ 3 Institute of General Pathology, Catholic University, Rome, Italy \\ ${ }^{4}$ Department of Organic and Biological Chemistry, University of Messina, Italy \\ * corresponding author: R. Scatena, Institute of Chemistry and Clinical \\ Chemistry, Faculty of Medicine, Catholic University, Largo Francesco Vito 1, \\ 00168 Rome, Italy. tel: +39-6-30154215; fax: +39-6-3053598; \\ e-mail: r.scatena@uniserv.ccr.rm.cnr.it
}

Received: 14.12.98; revised: 31.5.99; accepted: 9.6 .99

Edited by T. Cotter

\begin{abstract}
Bezafibrate belongs to the class of fibric acid derivatives usually used as antihyperlipidemia agents. From the biochemical point of view, these drugs show intriguing properties which leads one to think they may promote a differentiation process in tumour cells. This new pharmacological activity of fibrates could partially depend on the induction of an oxidative stress. To test this hypothesis, the effect of bezafibrate, as well as of clofibric acid and gemfibrozil, on growth, functional and cytochemical characteristics of human leukaemia-derived cell lines HL-60, U-937 and K- 562 has been studied in some details. The results show that bezafibrate, gemfibrozil and clofibric acid, do induce differentiation in human myeloid leukaemia cell lines as indicated by several differentiation markers. Moreover fibrates, in dose dependent manner, significantly alter the cell cycle distributions, mainly leading to $G_{0} / G_{1}$ phase increment and $G_{2} / M$ phase reduction. The differentiating activity of fibrates could have significant implications both for the pharmacotoxicological profile of this class of compounds and for the pathophysiology of neoplastic disease.
\end{abstract}

Keywords: bezafibrate; gemfibrozil; clofibric acid; reactive oxygen species (ROS); oxidative stress; cancer; differentiation

Abbreviations: NAC, N-acetyl-cysteine; DMSO, dimethylsulfoxide; BZF, bezafibrate; ATRA, all-trans retinoic acid; ROS, reactive oxygen species; ROM, reactive oxygen metabolism

\section{Introduction}

The use of differentiating factors in the treatment of cancer arises from the observation that some substances (retinoids, inhibitors of nucleic acid synthesis, polar/apolar compounds, etc.) are known to induce, in transformed cells, the expression of characteristics of differentiated cells and, above all, to reduce abnormal proliferation. In some cases, such as that of retinoids, the mechanism of action appears sufficiently clear while for others (DMSO, butyric acid), the cellular and molecular basis of the induced differentiation process, is still not completely understood.

Fibric acid derivatives are well-known antihyperlipoproteinemias drugs, that besides the disputed effects on lipid metabolism, have other different and intriguing properties, which are: (i) an activity as peroxisomes proliferators, particularly at hepatocyte and renal level; ${ }^{1}$ (ii) an inhibitory activity of the mitochondrial respiratory chain, particularly at the level of cytochrome c reductase; ${ }^{2}$ (iii) a strong allosteric interaction with human haemoglobin with a consequent reduction of oxygen affinity; ${ }^{3,4}$ (iv) a stimulatory action at the level of genes codifying for cytochrome P450 IV family ${ }^{1}$ and (v) a myotonic-like activity, which may be accompanied by muscular disorders resembling, from the clinical and pathological point of view, those characteristics of myotonic dystrophy. ${ }^{5}$

Considering these intriguing biochemical properties and in particular the inhibitory effect of the respiratory chain which could be well associated to a significant production of oxygen free radicals which reinforce oxidative stress secondary to enhanced peroxisomial beta-oxidation, ${ }^{1,6}$ we thought that fibrates could act as differentiating agents and promote the differentiation of tumour cells by inducing a significant imbalance in cellular oxidative metabolism.

To test this hypothesis, we have characterised the effect of bezafibrate and other fibric acid derivatives on the differentiation, growth rate and cell cycle patterns of HL-60, U-937 and K562 cell lines.

\section{Results \\ Differentiating activity of fibric acid derivatives}

Cell viability and inhibition of cell growth Figure 1 shows the effect of different concentrations of bezafibrate on cell growth for HL-60, U-937 and K562 human myeloid cell lines, cultured for 6 days.

In vitro, bezafibrate showed a significant inhibitory effect on the growth rate of all human cell lines examined. In particular, the growth curve of HL-60, expressed as area under curve (AUC), with respect to vehicle, is inhibited by the presence of $0.1,0.25,0.5$ and $1 \mathrm{mmol} / \mathrm{L}$ of bezafibrate by $27 \%(P<0.05), 30 \%(P<0.05), 33 \%(P<0.05)$ and $39 \%$ $(P<0.01)$, respectively. In the case of $U-937$ cells, the observed dose dependent inhibition corresponds to $6 \%$ for $0.1 \mathrm{mmol} / \mathrm{l}, 9 \%$ for $0.25 \mathrm{mmol} / \mathrm{L}, 25 \%(P<0.01)$ for $0.5 \mathrm{mmol} / \mathrm{L}$ and $46 \%(P<0.01)$ for $1 \mathrm{mmol} / \mathrm{L}$ of bezafibrate. Cell growth inhibition, for K562 cells, results to be of 9, 15 and $26 \%(P<0.05)$, and $40 \%(P<0.01)$, for $0.1,0.25$, 0.5 and $1 \mathrm{mmol} / \mathrm{L}$ respectively (Figure 1 ). 
In the same experimental conditions, all-trans retinoic acid (ATRA) $1 \mu \mathrm{mol} / \mathrm{L}$, used as positive control, reduced cell growth of HL-60, U-937 and K562, by $34 \%(P<0.01)$, $37 \%(P<0.01)$ and $14.5 \%(P<0.05)$ respectively (data not shown).

This inhibitory effect does not seem to depend on a direct cytotoxic action of the drug. In fact, in all cell lines, viability indexes (live cells number/total cells number $\times 100$; treated cell number/vehicle cell number $\times 100$, lactate dehydrogenase activity levels) appear significantly modified by bezafibrate only after the full appearance of differentiation-related phenotypes. From this point on, in bezafibrate-treated cells the typical pattern of morphological and molecular changes of apoptosis appear.

Remarkable are results about cell viability in monocytes and lymphocytes obtained from healthy volunteers incubated with bezafibrate in the same experimental conditions of the described cell line cultures. This set of experiments did not show any significant toxicity induced by the drug in the primary cell cultures.

Cell cycle distribution In the case of HL-60 cell line, the cell cycle distribution, for bezafibrate-treated cells, shows a dose-dependent reduction of the $\mathrm{G}_{2} / \mathrm{M}$ phase. With respect to vehicle, cell population is reduced by $5 \%$ and $20.4 \%$ $(P<0.05)$ and $40 \%(P<0.01)$ when in the presence of 0.1 , 0.5 and $1 \mathrm{mmol} / \mathrm{L}$ of bezafibrate respectively. In parallel, the S-phase was reduced by bezafibrate. Finally, the $\mathrm{G}_{0} / \mathrm{G}_{1}$ phase is increased by 2, 7 and $19 \%$ respectively $(P<0.05)$ (Figure 2).

U-937 and K562 cells show a similar pattern of modifications for the cell cycle distribution.

Functional, immunological and cytochemical differentiation assays Bezafibrate is effective in inducing a differentiation process in HL-60, $\mathrm{U}-937$ and $\mathrm{K} 562$ cell lines as demonstrated by functional, immunological and cytochemical assays.

Functional assays In human myeloid tumour cell lines, restoration of the so-called respiratory burst can be considered a fundamental functional marker of differentiation. This aspect of the phagocytes oxidative metabolism has been analyzed by chemiluminescence

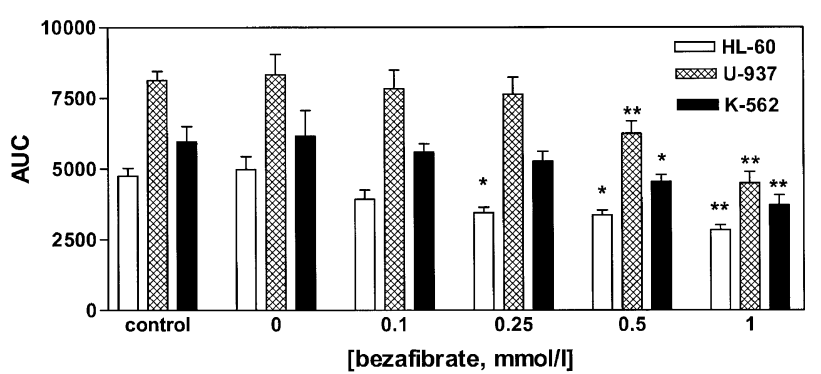

Figure 1 Effects of different concentrations of bezafibrate on HL-60, U-937 and K562 cell growth curves. Data are expressed as AUC (mean \pm S.E.M. $n=4$ ) considered after 6 days of culture. ${ }^{*} P<0.05 ;{ }^{* \star} P<0.01$
(CL). In particular, the results indicate that HL-60 cells, incubated with increasing concentrations of bezafibrate for 4 days, and thereafter stimulated by PMA or zymosan, do recover the oxidative burst in a dose-dependent manner (Figure 3A).

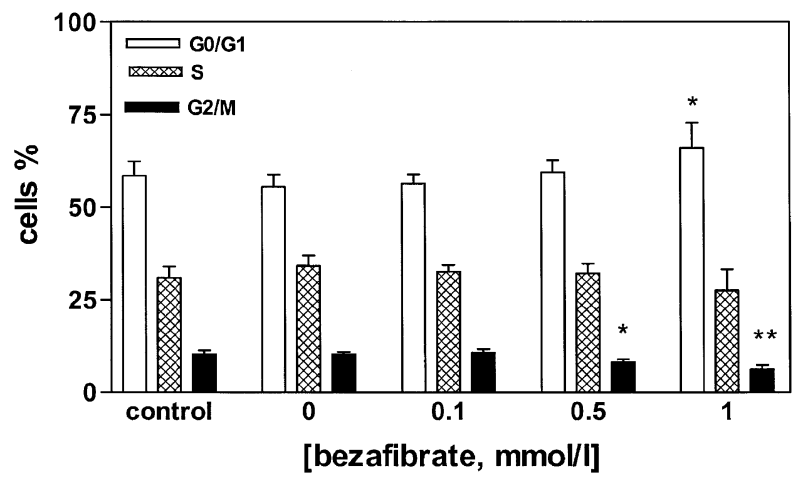

Figure 2 Cell cycle distribution of HL-60 cell line treated with different concentrations of bezafibrate for 3 days. Each point is the mean \pm S.E.M. $(n=4) .{ }^{*} P<0.05 ;{ }^{* *} P<0.01$
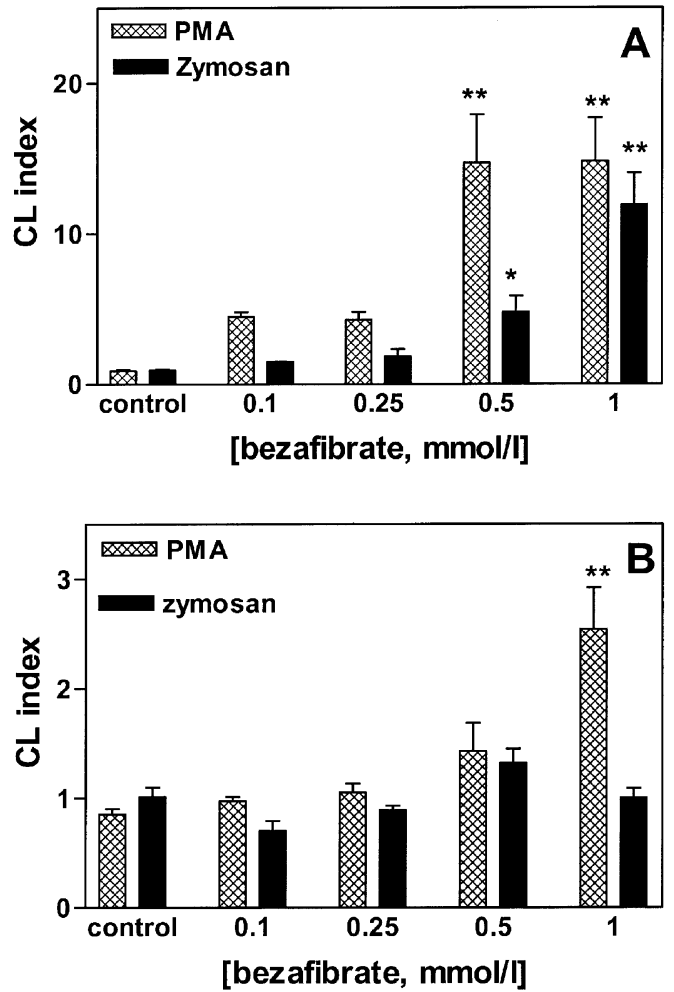

Figure 3 Concentration-dependent effect of bezafibrate on differentiation of HL-60 (A) and U-937 cells (B). The cells were cultured with various concentrations of bezafibrate for 4 and 6 days, respectively. Differentiationinducing activity was measured by chemiluminescence $(C L)$ as described in Materials and Methods. Each point is the mean \pm S.E.M. $(n=4)$. ${ }^{*} P<0.05$; ${ }^{* *} P<0.01$ 
U-937 cell line recovers an oxidative burst only when stimulated by PMA, reaching the maximum $\mathrm{CL}$ activity later than HL-60 cell line (Figure 3B).

Cytochemical differentiation assay In K562 cell line, benzidine staining has been adopted to point out haemoglobin accumulation, which is linked to activation of the differentiation process. The results clearly indicate a dose-dependent increase of haemoglobin synthesis with a maximum effect around day 8 of culture (Figure 4). With respect to vehicle-treated cells, the increment in haemoglobin synthesis is 1.7 (N.S.), $3.2(P<0.01), 3.9$ $(P<0.01)$ and $5(P<0.01)$, for $0.1,0.25,0.5$ and $1 \mathrm{mmol} / \mathrm{L}$ bezafibrate, respectively.

Surface markers expression Bezafibrate treatment induced a significant increase of the expression of CD11c and CD14 in a dose-dependent manner. In particular, at fifth day of culture, with respect to vehicle, CD14 appears to be increased by $1.5(P=\mathrm{NS}), 3.5(P<0.05)$ and $5.7(P<0.01)$ for $0.1,0.5$ and $1 \mathrm{mmol} / \mathrm{L}$ of bezafibrate, respectively (Figure 5); in parallel, the CD11c increase is $1.0(P=\mathrm{NS})$, $2.6(<0.05)$ and $7.5(P<0.01)$ for $0.1,0.5$ and $1 \mathrm{mmol} / \mathrm{L}$, respectively (Figure 5 ).

When HL-60 cells are treated with ATRA, used as positive control, the increment of CD11c expression is similar to that obtained with bezafibrate $1.0 \mathrm{mmol} / \mathrm{L}$. On the contrary, ATRA treated cells did not show any modification of CD14 expression (data not shown).

Bezafibrate-treated U-937 cells only show a dosedependent increment of the expression of CD14.

Other fibric acid derivatives To demonstrate that the antiproliferative/differentiating activity is not a unique property of bezafibrate, being a characteristic of the class of fibric acid derivatives, experiments with other well-known fibrates, such as clofibric acid and gemfibrozil, have been performed. For HL-60 cell line, the inhibition of growth obtained by clofibric acid is $13,18.5$ and $24.5 \%$ for 0.11 ,



Figure 4 Concentration-dependent effect of bezafibrate on differentiation of K562 cells. The cells were cultured with various concentrations of bezafibrate for 7 days. Differentiation-inducing activity was measured by benzidine staining as described in Materials and Methods. Each point is the mean + S.E.M. $(n=4) .{ }^{*} P<0.05 ;{ }^{*} P<0.01$
0.22 and $0.7 \mathrm{mmol} / \mathrm{L}$ of drug concentration, respectively (Figure 6). For the same type of cells, gemfibrozil 0.056 , 0.11 and $0.22 \mathrm{mmol} / \mathrm{L}$ causes a cell growth inhibition of 8.5 ,

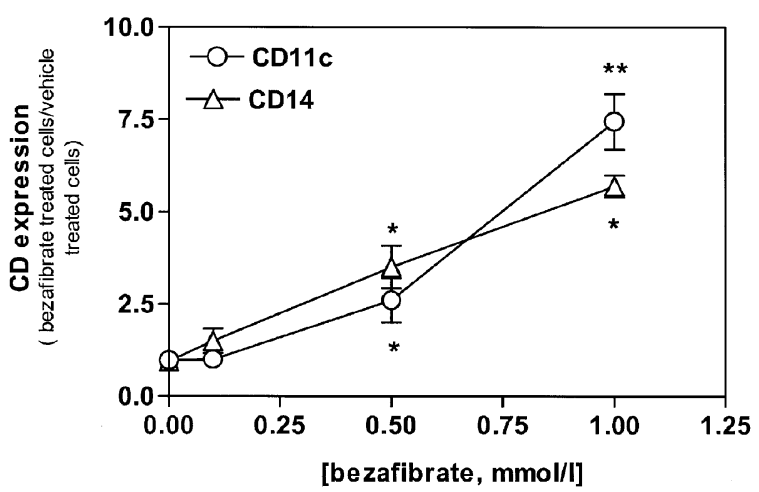

Figure 5 Effect of bezafibrate on the expression of CD11c and CD14. HL-60 cells in logarithmic growth phase were treated with different concentrations of bezafibrate or vehicle, as described in Materials and Methods. After $72 \mathrm{~h}$ the cells were analyzed for CD11C and CD14 expression. Each point is the mean \pm S.E.M. $(n=3) .{ }^{*} P<0.05 ;{ }^{* *} P<0.01$
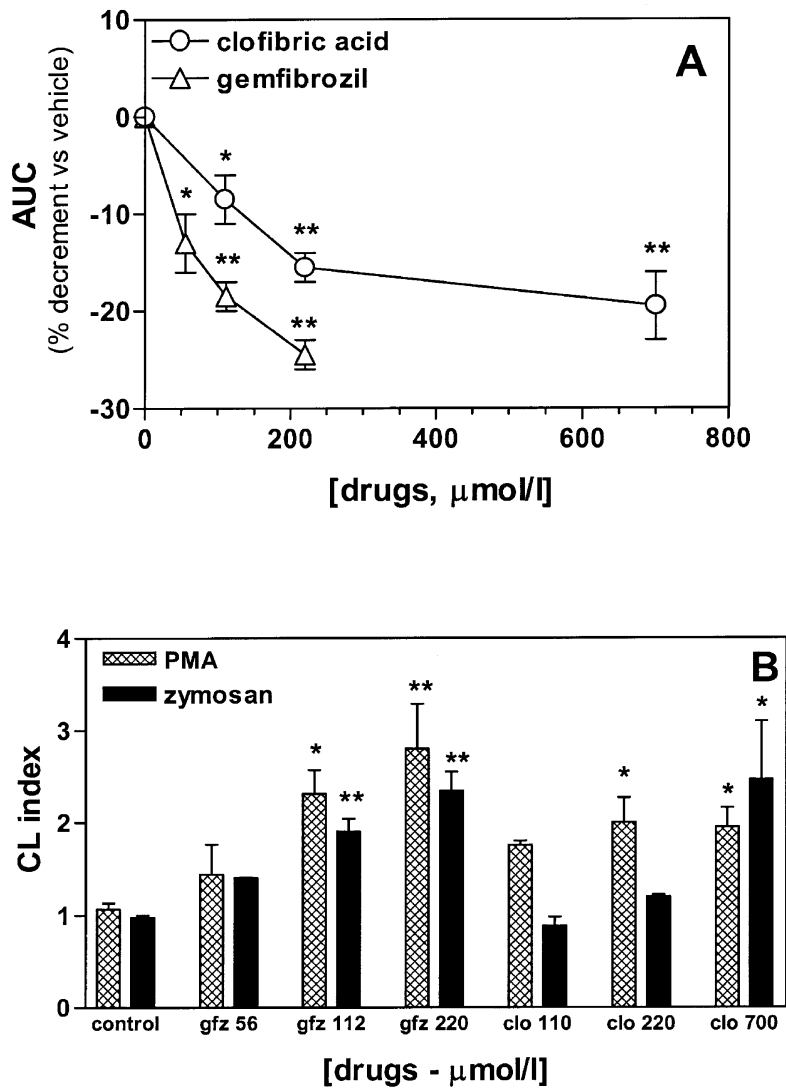

Figure 6 Concentration-dependent effects of a single administration of clofibric acid and gemfibrozil on HL-60 cell proliferation (A) and differentiation (B). The cells were cultured with various concentrations of the drugs for 4 days. Cell proliferation was expressed as AUC (per cent decrement versus vehicle). Differentiation-inducing activity was measured by chemiluminescence (CL) as described in Materials and Methods. Each point is the mean \pm S.E.M. $(n=4) .{ }^{*} P<0.05 ;{ }^{* *} P<0.01$ 
15.5 and $19.5 \%$, respectively. Moreover, clofibric acid and gemfibrozil treated HL-60 cells show a dose-dependent recovery of ROS metabolism, when stimulated both by PMA and zymosan (Figure 7).

Similarly to bezafibrate treated cells, an increment of CD11c expression and a decrement of $G_{2} / M$ and S-phase, both dose dependent, has been observed in clofibric acid and gemfibrozil treated HL-60 cell line (data not shown).

\section{Effect of antioxidants on differentiation induced by bezafibrate}

To test our hypothesis about a role for a derangement of cellular oxidative metabolism in the differentiation activity of fibrates, a set of functional and cytomorphological assays were realised in presence of a well-known antioxidant agent (N-acetylcysteine-NAC-).

Results indicate that NAC does influence differentiating activity of bezafibrate in terms of functional, immunological and cytochemical assays on HL-60, U-937 and K-562 cell lines.

In particular, data about phagocytes oxidative metabolism, analyzed by chemiluminescence (CL), showed that $\mathrm{HL}-60$ cells, treated with bezafibrate $1 \mathrm{mmol} / \mathrm{L}$ plus $\mathrm{NAC}$ $4 \mathrm{mmol} / \mathrm{L}$, and thereafter stimulated by PMA or zymosan, characterized by a significant reduction of the recovered oxidative burst activity with respect to same cells treated with bezafibrate $1 \mathrm{mmol} / \mathrm{L}$ alone (Table 1 ). In parallel, the expression of clusters of differentiation is diminished by the presence of NAC. In fact, CD14 and CD11c expression for HL60 did significantly decrease in bezafibrate plus NAC
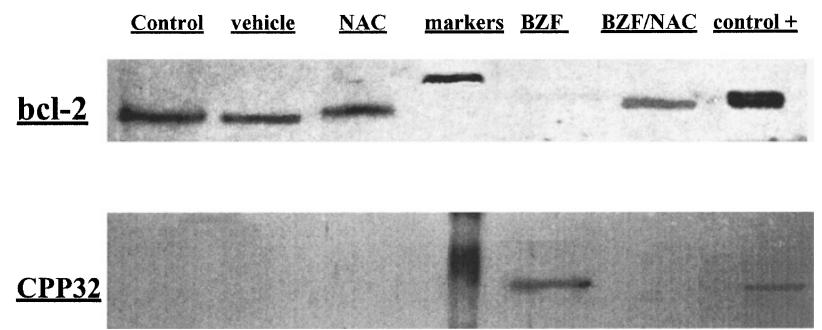

Figure 7 Western blot analysis of bcl-2 and CPP32 proteins in HL-60 cells treated with bezafibrate $1 \mathrm{mmol} / \mathrm{l}$ and/or NAC ( $4 \mathrm{mmol} / \mathrm{l})$ (see Materials and Methods) treated cell $(-88 \%, P<0.01 ;-82 \%, P<0.05$, respectively) with respect to bezafibrate $1 \mathrm{mmol} / \mathrm{L}$ alone (Table 1 ).

U-937 cells showed a similar pattern of modifications about the considered differentiation markers (CL index and CD14 expression) in bezafibrate $1 \mathrm{mmol} / \mathrm{L}$ plus NAC $4 \mathrm{mmol} / \mathrm{L}$ treated cell with respect to bezafibrate $1 \mathrm{mmol} / \mathrm{L}$ alone (data not shown). Considering K562 cells, haemoglobin accumulation was significantly higher in bezafibrate treated samples than in bezafibrate plus NAC ones (Table 2). Intriguingly, on the contrary to functional and immunological parameters, growth data indicate that NAC did not influence the inhibitory effect of bezafibrate on proliferation rate in $\mathrm{HL}-60, \mathrm{U}-937$ and $\mathrm{K} 562$ cells (Tables 1 and 2). Interestingly, Bcl-2 protein expression clearly appeared down regulated in bezafibrate-treated HL-60 cells and this down-regulation was partially reversed bezafibrate plus NAC treated cells (Figure 7). On the contrary, bezafibrate showed to induce a new expression of CPP32-caspase 3. The presence of NAC blocked this new expression (Figure 7).

\section{Discussion}

The main target of differentiation agents is the return toward normal of the relationship of proliferation to differentiation. ${ }^{7}$

Differentiation therapy could be considered an elegant pharmacological approach to cancer, which should not be limited to particular types or staging of cancer. In differentiation therapy the cells are treated with agents that should force them to mature, thereby becoming less proliferative. Such a therapy is becoming an attractive

Table 2 Effects of $\mathrm{N}$-acetylcysteine $(4 \mathrm{mmol} / \mathrm{l})$ on $\mathrm{K}-562$ cells differentiation induced by bezafibrate $1 \mathrm{mmol} / \mathrm{l}$

\begin{tabular}{lcc}
\hline & $\begin{array}{c}\text { Cell growth } \\
(n=5)\end{array}$ & $\begin{array}{c}\text { Benzidine test } \\
(n=5)\end{array}$ \\
\hline Control & $1.01 \pm 0.1$ & $1.13 \pm 0.1$ \\
N-acetylcysteine (Nac) & $0.96 \pm 0.1$ & $1.00 \pm 0.1$ \\
Bezafibrate & $0.62 \pm 0.1^{\star *}$ & $2.85 \pm 0.2^{\star *}$ \\
Bezafibrate/Nac & $0.70 \pm 0.1^{\star *}$ & $1.00 \pm 0.2$ \\
& \$Bezafibrate vs & §Bezafibrate vs \\
& bezafibrate plus & bezafibrate plus \\
& Nac: $P=N S$ & Nac: $P<0.05$ \\
\hline
\end{tabular}

$P<0.05 ;{ }^{* *} P<0.01$. Analysis of variance (ANOVA) followed by a multiple comparison of means by Dunnet test. $\S$ : analysis of variance (ANOVA) followed by Student-Newman-Keuls was used

Table 1 Effects of $\mathrm{N}$-acetylcysteine $(4 \mathrm{mmol} / \mathrm{l})$ on $\mathrm{HL}-60$ cells differentiation induced by bezafibrate $1 \mathrm{mmol} / \mathrm{l}$

\begin{tabular}{|c|c|c|c|c|c|}
\hline & \multirow{2}{*}{$\begin{array}{l}\text { Cell growth } \\
\qquad(n=5)\end{array}$} & \multicolumn{2}{|c|}{$\begin{array}{c}\text { CL index } \\
(n=5)\end{array}$} & \multicolumn{2}{|c|}{$\begin{array}{c}\text { CD expression } \\
(n=3)\end{array}$} \\
\hline & & PMA & Zymosan & CD 14 & CD 11c \\
\hline Control & $0.90 \pm 0.2$ & $0.97 \pm 0.7$ & $1.07 \pm 0.1$ & $1.2 \pm 0.1$ & $0.9 \pm 0.3$ \\
\hline $\mathrm{N}$-acetylcysteine (Nac) & $0.96 \pm 0.3$ & $1.17 \pm 0.1$ & $1.38 \pm 0.1$ & $0.7 \pm 0.3$ & $1.4 \pm 0.7$ \\
\hline Bezafibrate & $0.58 \pm 0.2^{* *}$ & $10.23 \pm 3.5^{*}$ & $17.65 \pm 2.6^{\star *}$ & $6.5 \pm 1.2^{*}$ & $3.90 \pm 1.3^{*}$ \\
\hline \multirow[t]{4}{*}{ Bezafibrate/Nac } & $0.55 \pm 0.2^{\star \star}$ & $5.45 \pm 1.9$ & $10.4 \pm 0.3$ & $0.8 \pm 0.2$ & $0.7 \pm 0.3$ \\
\hline & $\S$ Bezafibrate vs & §Bezafibrate vs & $\S$ Bezafibrate vs & $\S$ Bezafibrate vs & $\S$ Bezafibrate vs \\
\hline & bezafibrate plus & bezafibrate plus & bezafibrate plus & bezafibrate plus & bezafibrate plus \\
\hline & Nac: $P=N S$ & Nac: $P<0.05$ & Nac: $P=<0.05$ & Nac: $P=<0.01$ & Nac: $P=<0.05$ \\
\hline
\end{tabular}

$P<0.05 ;{ }^{*} P<0.01$. Analysis of variance (ANOVA) followed by a multiple comparison of means by Dunnet test. $\S$ : analysis of variance (ANOVA) followed by StudentNewman-Keuls was used 
alternative in cancer treatment, as neoplastic transformation is considered to be a result from defects in cellular differentiation. ${ }^{8}$ From a pharmacological point of view, the main advantage of this particular adjuvant therapeutic approach could be represented, with respect to conventional chemotherapy, by both a minor incidence of side effects and a broader spectrum of indications (leukaemias, lymphomas, solid tumours and above all SNC tumours, independently from hystologic type and/or TNM classification).

From a biochemical point of view, the use of differentiating agents could represent a further way to elucidate the molecular mechanisms at the basis of neoplastic transformation.

In this respect, the intriguing biochemical activities of bezafibrate, that is a well-known drug still used in the usual antihyperlipoproteinemia therapeutic protocols, ${ }^{9}$ push us to verify, as first aim, its potential differentiating activity. Moreover, as secondary aim, we tried to find indications about a possible link between this activity and the wellknown cellular oxidative metabolism imbalance caused by fibric acid derivatives.

Results clearly indicate that bezafibrate, in dosedependent manner, reduces cellular proliferation in different human leukaemia cell lines. According to cell growth and cell cycle assays, this antiproliferative effect seems to depend on a cytostatic activity with no or poor direct acute cytotoxic effect (apoptosis and/or necrosis). Moreover, the effect on cell proliferation appears qualitatively comparable to ones observed with other well-known differentiating factors (ATRA $1 \mu \mathrm{mol} / \mathrm{L}$; DMSO 1.3\%).

Differentiation assays realised on HL-60 and U-937 cells lines showed, in dose dependent manner, a typical recovery of ROS metabolism, as indicated by data on chemiluminescence obtained in unstimulated and PMA or zymosan stimulated cells (Figure 3). Interestingly, HL-60 showed to recover a typical ROS metabolism both adopting as stimulus PMA and zymosan. The presence of PMA induced $\mathrm{CL}$ seems to demonstrate an acquired right assembly of NADPH oxidase system. Zymosan induced $\mathrm{CL}$ could be considered a result obviously related to the acquired function of a Fc receptor on cell membrane, according to $C D$ assay results. Differently, U-937 cells show to significantly recover only PMA induced $C L$ and the level of the new acquired ROS metabolism appeared significantly lower than that of bezafibrate treated HL-60 cells.

CDs expression does confirm cell growth and cell CL data, indicating both in HL-60 and U-937 cell lines, a bezafibrate-induced maturation towards monocyte-macrophage lineage. This is confirmed by the significant dosedependent increase of the expression of CD11C and CD14 for HL-60 cell line and CD14 for U-937 cell line.

Finally the results on K562 cell line considered in terms of mielomonocytic and erythroid differentiation, results clearly indicate a bezafibrate-induced maturation towards erythroid lineage.

Experiments realised with NAC to point out a possible role for the oxidative stress on bezafibrate induced differentiation clearly show that this antioxidant, only administered at day 0 of culture, may significantly inhibit bezafibrate induced differentiation, in terms of cytochemical and functional assays in HL-60, U-937 and K562 cell lines (Tables 1, 2). Interestingly, NAC can partially inhibit downregulation of $\mathrm{Bcl}-2$ protein expression and seems to completely prevent the expression of CPP32 protein in HL-60 cells treated with bezafibrate (Figure 7).

However, data about cell proliferation did not show any modification in bezafibrate plus NAC treated cells with respect to bezafibrate treated cells in all considered cell lines. These particular data should be further analyzed to better clarify this diverse and intriguing way of action. This former result, in our opinion, could indicate that the mitochondrial derangement represents the first lesion induced by fibrate at cellular level.

In conclusion, this study does confirm the differentiating activity of fibric acid derivatives and seems to point out that the well-known cellular oxidative stress, induced by these drugs, could have a role in promoting the differentiation process of neoplastic cells. From a biochemical point of view, the differentiating activity of fibrates could be used to clarify some molecular mechanisms, in terms of activation of signal transduction pathways and/or mitochondria/ citoplasmatic modulation of tumour suppressor genes and oncogene expression, implicated in the pathophysiology of oxidative stress-related differentiation processes. Moreover, data regarding differentiating activity of fibric acid derivatives seems to give a new light on the pathophysiology of the dedifferentiation process in cancer.

In summary, on the basis of the above reported results, we are faced with the following:

- The precise mechanism of mitochondria damage and its consequence in terms of cellular oxidative metabolism imbalance;

- The interrelationships between peroxisome proliferator activity and mitochondrial damage

- The compensatory machinery (essentially in terms of HSP induction) implicated in the maintenance of cellular homeostasis and its role in promoting the differentiation state;

- The meaning of such a compensatory mechanism in a peripheral modulation of tumour suppressor genes and/ or oncogenes expression;

- The role of this particular class of differentiating factors in a new definition of dedifferentiation/differentiation processes in cancer.

\section{Materials and Methods}

\section{Cell culture}

Prof. A. Cittadini (Institute of General Pathology, Faculty of Medicine, Catholic University, Rome, Italy) kindly supplied human acute promyelocytic leukaemia HL-60 cell line. Human histiocytic lymphoma U-937 cell line and human chronic myelogenous leukaemia K562 cell line were obtained from Interlab Cell Line Collection (CBA) (Genoa, Italy). Cells were maintained at $37^{\circ} \mathrm{C}$ under a humidified atmosphere of $5 \% \mathrm{CO}_{2}$ in RPMI 1640 HEPES modified medium supplemented with 
$10 \%(\mathrm{v} / \mathrm{v})$ heat inactivated foetal calf serum, $2 \mathrm{mM}$ glutamine, $100 \mathrm{IU} /$ $\mathrm{ml}$ penicillin and $100 \mu \mathrm{g} / \mathrm{ml}$ streptomycin.

\section{Materials}

Unless indicated all chemicals and reagents (cell culture grade) were obtained from Sigma Chemical Co., Milan, Italy.

\section{Cell viability and proliferation assay}

Cell number was determined using a Neubauer hemocytometer, and viability was assessed by their ability to exclude trypan blue. Cytostatic activity determined by microscopic assay was confirmed in an alternative assay by measuring MTT (3-(4,5-dimethylthiazol-2-yl)-2,5 diphenyltetrazolium bromide) reductase activity. ${ }^{10}$ Assay were performed in quintuple at different fibrates concentrations in 96 well plates (Costar, Boston, MA, USA). These two growth and viability assay produced essentially the same results. Apoptotic cells were identified by fluorescence microscopy and by DNA electrophoresis as described. $^{11}$

\section{Drugs treatment}

The stock solutions were prepared immediately before use. Bezafibrate, gemfibrozil and clofibric acid were dissolved in DMSO at various concentrations ranging from 0.1 to $1 \mathrm{~mol} / \mathrm{L}$. All-trans retinoic acid was dissolved in DMSO at concentration of $1 \times 10^{-3} \mathrm{~mol} / \mathrm{L}$. HL$60, \mathrm{U}-937, \mathrm{~K} 562$ exponentially growing cells $\left(3 \times 10^{5} \mathrm{cells} / \mathrm{ml}\right)$ were set at day 0 in media containing various concentrations of drugs or ATRA ( $1 \mu \mathrm{mol} / \mathrm{L}$ final concentration) or DMSO 1.3\% (final volume) for 3-14 days). The final concentration of the drugs were: bezafibrate, $1 \times 10^{-4}, 2.5 \times 10^{-4}, 5 \times 10^{-4}$ and $1 \times 10^{-3} \mathrm{~mol} / \mathrm{L}$; gemfibrozil, $5.6 \times 10^{-5}, 1.12 \times 10^{-4}$ and $2.3 \times 10^{-4} \mathrm{~mol} / \mathrm{L}$; clofibric acid, $1.1 \times 10^{-4}, 2.23 \times 10^{-4}, 7.00 \times 10^{-4} \mathrm{~mol} / \mathrm{L}$, respectively. The final concentration of DMSO, used as vehicle, was the same in all samples during the experiments, $(0.1 \% \mathrm{v} / \mathrm{v})$.

In a set of experiments, $\mathrm{HL}-60$ cell line were induced to differentiate in presence of $\mathrm{N}$-acetyl cysteine (NAC - concentrations ranging from 4 to $20 \mathrm{mmol} / \mathrm{L}$ ) dissolved in $\mathrm{NaOH}$ buffered Krebs-Ringer-Phosphate (KRP) solution, butylated hydroxyanisole (-BHA- 100 and $200 \mu \mathrm{mol} / \mathrm{L}$ dissolved in ethanol $0.1 \%)$ and Tocopherol (100 $\mu \mathrm{mol} / \mathrm{L}$-dissolved in DMSO $0.05 \%$ ). In this set of experiments antioxidant agents were administered only once at day 0 to the cell cultures.

\section{Cell cycle distribution assay}

Analysis of the DNA content of cells and their distribution within $G_{1}, S$ and $G_{2} / M$ phases of the cell cycle was realised by flow cytometry according to the method of Crissman, ${ }^{12}$ adopting propidium iodide as fluorochrome (Molecular Probes Europe BV, Leiden, The Netherlands).

\section{Differentiation assays}

Functional assay Phorbol-12-Myristate-13-Acetate (PMA) and zymosan stimulated reactive oxygen species (ROS) metabolism, essentially due to the activity of NADPH oxidase system, was adopted as marker of differentiation in human myeloid cell line HL-60 and U-937. ROS metabolism was studied by a chemiluminescence $(\mathrm{CL})$ assay as described. ${ }^{13}$

Luminol, the chemiluminigenic probe, and PMA stock solutions were prepared respectively 50 and $3 \mathrm{mmol} / \mathrm{L}$ in dimethylsulphoxide.
The working solution, a modified Krebs Ringer phosphate (KRP) medium containing $119 \mathrm{mmol} / \mathrm{L} \mathrm{NaCl}, 4.8 \mathrm{mmol} / \mathrm{KCl}, 1.2 \mathrm{mmol} / \mathrm{L}$ $\mathrm{MgSO}_{4}, 5.5 \mathrm{mmol} / \mathrm{L}$ glucose, $0.25 \mathrm{mmol} / \mathrm{L} \mathrm{CaCl} 2,16.6 \mathrm{mmol} / \mathrm{L}$ phosphate buffer $\mathrm{pH} 7.4$, was prepared immediately before use. Zymosan was prepared and opsonised as described previously. ${ }^{14}$ Briefly, $25 \mathrm{mg}$ of zymosan were incubated for $20 \mathrm{~min}$ at $37^{\circ} \mathrm{C}$ in $1.0 \mathrm{ml}$ fresh plasma obtained from a pool of at least ten blood donors. After three washings, the opsonified zymosan was diluted to $5 \mathrm{mg} / \mathrm{ml}$. Each sample was stimulated with PMA and/or opsonized zymosan. ROS production was measured by luminol amplified luminescence. Assays were performed in triplicate in an automatic luminometer (Autolumat LB 953, EG\&G, Turku, Finland) at $25^{\circ} \mathrm{C}$ for $120 \mathrm{~min}$ with cycles of $5 \mathrm{~min}$ each. Chemiluminescence system contained: $1 \times 10^{5}$ cells, without treatment (control), or treated with $0.1 \%$ DMSO (vehicle alone), or cells treated with different differentiating factors, $100 \mathrm{nmol}$ of luminol, $0.5 \mathrm{mg}$ of opsonized zymosan or $150 \mathrm{pmol}$ of PMA in $1.0 \mathrm{ml}$ final volume with KRP solution. Unstimulated activity was measured without addition of any stimulus.

The considered $\mathrm{CL}$ parameters were: (a) Stimulation index (SI):

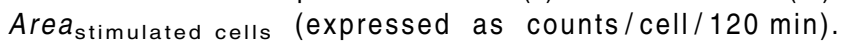
Area $a_{\text {unstimulated cells. (expressed as counts/cell/120 min.) (b) } \mathrm{CL}}$ index: $S I$ bezafibrate-treated cells $/ S I$ vehicle-treated cells

Cytomorphological assay for K562 cell line differentiation The most widely used method for scoring erythroid differentiation is benzidine staining which reveals the production of hemoglobin. ${ }^{15}$ Benzidine dihydrochloride $\left(2 \mathrm{mg} / \mathrm{ml}\right.$ ) was prepared in $3 \%$ acetic acid. $\mathrm{H}_{2} \mathrm{O}_{2}(1 \%)$ was added immediately before use. The $\mathrm{K} 562$ cell suspensions were mixed with the benzidine solution in a $1: 1$ ratio and counted in a hemocytometer after $5 \mathrm{~min}$. Blue cells were considered to be positive for haemoglobin.

The considered benzidine liquid staining parameter was:

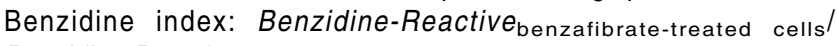
Benzidine-Reactive vehicle-treated cells

Surface marker expression The differentiation-related phenotypes were analyzed by direct immunufluorescence staining and flow cytometry according to a standard method. ${ }^{16}$ In particular, the following cell surface antigens were considered: CD11c, CD11b, CD14 (Anti-Human Leucocyte Antibodies were from Becton Dickinson, Milan, Italy).

Western blot analysis Western blot analysis were realised according to the described protocol. ${ }^{17}$ Briefly, cells were washed in PBS and resuspended in $20 \mathrm{mM}$ Tris- $\mathrm{HCl}$ and $5 \mathrm{mM} \mathrm{MgCl} \mathrm{MH}_{2}(\mathrm{pH}$ 7.5) and immediately heated at $100^{\circ} \mathrm{C}$ for $10 \mathrm{~min}$. Subsequently, samples were mixed with an equal volume of a $2 \times$ urea-glycerol-SDS solution and heated at $100^{\circ} \mathrm{C}$ for $10 \mathrm{~min}$. Protein concentration of the samples was determined using detergent-compatible reagents (Bio-Rad Laboratories, USA). Protein extracts $(60 \mu \mathrm{g})$ were subjected to electrophoresis in a $12 \%$ SDS polyacrylamide gel. Monoclonal anti-Bcl-2 (mouse IgG1 isotype) was used at a dilution of 1:500. Monoclonal antiCPP32/Caspase 3 (mouse IgG2a isotype) was used at a dilution of 1:1000. All antibodies were from Transduction Laboratories (Lexington, KY, USA). Western blots were analyzed using the Amplified Opti-4 CN detection kit (Bio-Rad Laboratories, USA).

Statistical analysis All results are expressed as mean \pm S.E.M. The group means were compared by analysis of variance (ANOVA) followed by a multiple comparison of means by Dunnet test. Upon occurrence multiple comparison of means by Student-Newman-Keuls was used. $P<0.05$ was considered significant. 


\section{Acknowledgements}

We are grateful to Institute of General Pathology, Catholic University of Rome, for the kindly technical assistance and for laboratory facilities.

\section{References}

1. Issemann I, Green S (1990) Activation of a member of the steroid hormone receptor superfamily by peroxisome proliferators. Nature 347: 645-649

2. Chance DS, McIntosh MK (1995) Hypolipidemic agents alter hepatic mitochondrial respiration in vitro. Comp. Biochem. Physiol. 111C: 317-323

3. Perutz MF, Poyart C (1983) Benzafibrate lowers oxygen affinity of hemoglobin. Lancet 2: $881-882$

4. Scatena R, Nocca G, Messana I, De Sole P, Baroni S, Zuppi C, Castagnola M, Giardina B (1995) Effects of gemfibrozil on the oxygen transport properties of erythrocytes. Br. J. Clin. Pharm. 39: 322-327

5. Harper S (1989) Myotonic dystrophy II, W.B. Saunders, London

6. Youssef J, Badr M (1998) Extraperoxisomal targets of peroxisome proliferators: mitochondrial, microsomal, and cytosolic effects. Implications for health and disease. Crit. Rev. Toxicol. 28: 1-33

7. Marks PA, Rifkind RA (1991) Differentiating factors. In Biologic Therapy of Cancer. De Vita V.T., Hellman S., Rosenberg S.A. Eds. (J.B. Lippincott Company, Philadelphia) pp. 754-762
8. Scott SE (1997) Differentiation, differentiation/gene therapy and cancer. Pharmacol Ter 73: 51-65

9. Brown MS, Goldstein JL (1990) Drugs used in the treatment of hyperlipoproteinemias. In The Pharmacological Basis of Therapeutics, Eighth Edition, eds Gilmann AG, Rall TW, Nies AS, (New York: Pergamon Press) pp. 874-896.

10. Skehan P (1995) Assay of cell growth and citoxicity. In Cell Growth and Apoptosis. Studzinski GP Eds (IRL Press, Oxford).

11. Ramachandra S, Studzinski P (1995) Morphological and biochemical criteria of apoptosis. In Cell Growth and Apoptosis. Studzinski GP Eds (IRL Press, Oxford) pp $119-142$

12. Crissman HA (1995) Cell cycle analysis by flow cytometry. In Cell Growth and Apoptosis. Studzinski GP Eds. (IRL Press, Oxford) pp 65-78

13. De Baetselier $P$, Scrham E (1986) Luminescent bioassay based on macrophage cell lines. Methods Enzymol. 133: 507-530

14. Allen RC (1986) Phagocytic leukocyte oxygenation activities and chemiluminescence: a kinetic approach to analysis. Methods Enzymol. 133: 449-492

15. Rowley PT, Ohlsson-Wilhelm BM, Farley BA, La Belle S (1981) Inducers of erythroid differentiation in K562 human leukemia cells. Exp. Hemat. 9: 32-38

16. Moretta L, Pende D, Varese P (1989) Marcatori linfocitari. In Immunologia e immunopatologia. Romagnani S, Moretta L Eds (USES, Firenze) pp 169-190

17. Han Z, Chatterejie D, Early J, Pantazis P, Hendrikson EA, Wyche JH (1996) Isolation and characterization of an apoptosis-resistant variant of human leukemia $\mathrm{HL}-60$ cells that has switched expression from Bcl-2 to Bcl- $\mathrm{X}_{\mathrm{L}}$. Cancer Res. 56: $1621-1628$ 